\title{
EFICIÊNCIA DOS MUNICÍPIOS MINEIROS: UMA ANÁLISE RELACIONADA ÀS ÁREAS DE MEIO AMBIENTE, HABITAÇÃO E URBANISMO
}

\section{EFFICIENCY OF MINAS GERAIS' MUNICIPALITIES: AN ANALYSIS RELATED TO THE AREAS OF ENVIRONMENT, HOUSING AND URBANISM}

0 artigo foi aprovado e apresentado no XVII Seminário sobre a Economia Mineira de 2016, realizado de 29 de agosto a 02 de setembro, em Diamantina (MG).

\begin{abstract}
RESUMO
As entidades públicas, em virtude da escassez de recursos e das necessidades sociais cada vez mais crescentes, devem buscar, constantemente, meios para avaliar as suas ações e políticas implementadas. A partir dessa ideia, este estudo objetivou identificar os fatores que determinam a eficiência dos municípios mineiros, no que diz respeito às áreas de meio ambiente, habitação e saneamento, de modo a maximizar o bem-estar social. A técnica empregada na análise da eficiência foi a Data Envelopment Analysis, com pressuposição de retorno variável à escala e orientação-produto. Na estimação, o output utilizado foi o Índice Mineiro de Responsabilidade Social dos municípios de Minas Gerais, do ano de 2010. Quanto aos inputs, foram considerados o percentual de esgoto tratado, domicílios com acesso à abastamento de água e coleta de lixo. Na sequência, para identificar os determinantes dos escores de eficiência, estimou-se um modelo Tobit, utilizando, como variáveis, a densidade demográfica, população urbana, Produto Interno Bruto per capita, gasto per capita com habitação, saneamento e meio ambiente e dummies de existência de conselhos de meio ambiente e habitação. Pelos resultados, identificaram 17 municípios com eficiência máxima, e as variáveis relevantes para explicar os escores foram densidade populacional, proporção de população urbana e existência de conselho municipal de meio ambiente.
\end{abstract}

Palavras-Chave: Análise Envoltória de Dados. Indicadores Sociais. Eficiência.

\begin{abstract}
Public entities, because of the scarcity of resources and growing social needs, should continuously seek ways to evaluate their actions and policies. From this idea, this study looked for identified the factors that determine the efficiency of the municipalities miners, with regards to the environment area, housing, and sanitation, the form to maximize the social welfare. The technique used in the analyze was the Data Envelopment Analysis, with the presupposition of the variable return of scale and production orientation. In the estimation, the output used was the Mineiro Social Responsibility Index (MSRI) of municipalities of Minas Gerais, the year of 2010. As for inputs, was using the percentual of treated sewage, households with access to water supply and garbage collection were considered. To identify the determinants of efficiency scores, a Tobit model was estimated, using, as variables, the population density, urban population, gross domestic product per capita, per capita expenditure with housing, sanitation and environment and dummies of advice on environment and housing. Based on the results, they identified 17 municipalities with maximum efficiency, and the relevant variables to explain the scores were population density, the proportion of the urban population and the existence of the municipal council of environment.
\end{abstract}

Keywords: Data Envelopment Analysis. Social Indicators. Efficiency.
Elizete Aparecida de Magalhães Doutora em Economia Aplicada pela Universidade Federal de Viçosa (UFV). Mestre em Administração pela Universidade Federal de Viçosa (UFV). Bacharela em Ciências Contábeis pela Universidade Federal de Viçosa (UFV). Professora Adjunta II do Curso de Ciências Contábeis, da Universidade Federal dos Vales do Jequitinhonha e Mucuri (UFVJM). Contato: Rua do Cruzeiro, $n^{0} 1$, Bairro Jardim São Paulo. CEP: 39803-371. Teófilo Otoni, MG E-mail: elizete.am@ufvim.edu.br.

Vasconcelos Reis Wakim Federal de Viçosa (UFV). Mestre em Desenvolvimento Regional e Agronegócio pela Universidade Federal do Tocantins (UFT). Especialista em Perícia Contábil pela Faculdade Ozanan Coelho de Ubá, MG (FAGOC). Bacharel em Ciências Contábeis pela Universidade Federal de Viçosa (UFV). Professor Adjunto II do Curso de Ciências Contábeis, da Universidade Federal dos Vales do Jequitinhonha e Mucuri (UFVJM). Contato: Rua do Cruzeiro, $n^{\circ} 1$, Bairro Jardim São Paulo. CEP: 39803-371. Teófilo Otoni, MG. E-mail: vasconcelos. wakim@ufvjm.edu.br.

\section{Adriano Provezano Gomes}

Doutor em Economia Aplicada pela Universidade Federal de Viçosa (UFV), Graduação em Engenharia Agronômica pela Universidade Federal de Viçosa (UFV). Professor Associado I do Curso de Ciências Econômica da Universidade Federal de Viçosa (UFV). Av. PH Rolfs, s/n. CEP: 36570-000. Viçosa, MG E-mail: apgomes@ufv.br. 


\section{INTRODUÇÃO}

A partir da década de 1990, o mundo despertou para os problemas socioambientais decorrentes das atividades econômicas. Inúmeros reflexos negativos provenientes do crescimento socioeconômico desordenado afloraram e a sociedade percebeu que deveria reverter este quadro. Nesta mesma linha de argumentação, Wakim, Vergara e Magalhães (2012) comentam que, com a necessidade de se buscar novas fontes alternativas de combustíveis, preservação dos rios de água doce, entre outros desafios, os pesquisadores estão empenhados em encontrar uma forma de minimizar os problemas ambientais e proporcionar à sociedade uma melhora na qualidade de vida.

Os chefes de Estado buscaram, a partir da realização de encontros, por diversos países, estratégias para mitigar os problemas socioambientais. Pode-se citar como exemplo, na década de 1980, um evento na cidade de Montreal, no Canadá, em que os principais líderes mundiais discutiram os problemas que estavam afetando a camada de ozônio, tendo como produto a elaboração de um documento, segundo o qual os países signatários deveriam reduzir a emissão dos gases que os prejudicavam. Outro exemplo é a Convenção-Quadro das Nações Unidas sobre Mudanças Climáticas, popularmente conhecida como ECO-92, que ocorreu na cidade do Rio de Janeiro, no ano de 1992. De acordo com Soares e Higuchi (2006), a Convenção-Quadro é um tratado de direito internacional, que deve ser implementado respeitando os ditames do direito internacional, bem como as regras internas do país. Este evento foi um marco para a história da sociedade, pois grande parte dos países que estiveram presentes ratificou a proposta de desenvolver ações que promovessem o desenvolvimento socioeconômico, de forma sustentável. Conforme menciona Novaes (1992), a Eco-92 proporcionou desdobramentos políticos, econômicos e sociais, relevantes para a sociedade internacional. No referido evento, dentre outros resultados importantes para a sociedade, pode-se destacar a institucionalização do termo desenvolvimento sustentável.

A origem do termo desenvolvimento sustentável é remontada ao relatório da primeira-ministra da Noruega, Gro Harlen Brundtland, chamado Nosso Futuro Comum, na década de 1980. É apontado no relatório que "a humanidade é capaz de tomar o desenvolvimento sustentável - de garantir que ele atenda às necessidades do presente sem comprometer a capacidade de as gerações futuras atenderem também às suas." (NOSSO FUTURO..., 1991, p. 9).

Outro produto, oriundo da ECO-92, é a denominada Agenda 21, em que as principais diretrizes eram as ações que os estados, municípios, União, entidades governamentais e não-governamentais deveriam executar para promover o desenvolvimento socioeconômico, de maneira sustentável, durante o século XXI. De acordo com o apresentado por Novaes (1992), os recursos anuais previstos para o desenvolvimento da Agenda 21 remontavam à ordem de US\$ 6,2 bilhões, por ano, destinados à preservação das florestas.

O Brasil, desde a ECO-92, vem buscando desenvolver programas sociais e ambientais que contribuam para o chamado desenvolvimento sustentável. Assim, o Estado deve empreender ações que garantam a sustentabilidade, gerando, desta maneira, ganho de bem-estar para a população local e, de forma indireta, para a sociedade global.

Buscando atender as diretrizes da Agenda 21, os municípios, dentro de suas capacidades financeiras e orçamentárias, têm buscado desenvolver ações em programas de habitação, urbanismo, saneamento básico, meio ambiente e outras áreas, que possibilitem gerar qualidade de vida para a população. Ressalta-se que, no ano de 2012, por exemplo, os municípios de Minas Gerais gastaram, com urbanismo, um montante médio per capita de R\$214,53 e, com habitação e saneamento, a média foi de $\mathrm{R} \$ 9,58$ e $\mathrm{R} \$ 48,21$, por habitante, respectivamente. (SECRETARIA DO TESOURO NACIONAL, 2015).

Desta forma, a busca pela qualidade social, econômica e ambiental perpassa pelas ações de investimento dos estados/municípios em programas socioeconômicos que proporcionam ganhos de bem-estar e qualidade de vida para os cidadãos. No entanto, para monitorar os resultados das políticas públicas, com o propósito de corrigir possíveis desvios, bem como constatar se os investimentos governamentais trouxeram efetivo resultado para a sociedade, é necessário criar e avaliar indicadores sociais.

Neste sentido, a Fundação João Pinheiro (FJP) desenvolveu o Índice Mineiro de Responsabilidade Social (IMRS), que visa medir a qualidade na percepção ambiental e urbanística dos municípios mineiros. Em outras palavras, este índice busca medir as ações dos gestores, tanto estadual quanto municipal, na geração de qualidade socioeconômica e ambiental à população mineira.

Considerando a necessidade de monitorar as condições de vida e bem-estar da sociedade pelo poder público e pela própria população, torna-se fundamental avaliar se as ações em termos de saneamento, habitação e meio ambiente dos municípios de Minas Gerais estão sendo implementadas de forma eficiente, ou seja, perceber se o setor público está conseguindo desenvolver suas ações, de modo a maximizar o resultado. Diante do exposto, este estudo visa identificar os determinantes da eficiência dos municípios mineiros, no que se refere às áreas de meio ambiente, habitação e saneamento.

O artigo está estruturado em cinco seções, incluído esta introdução. A segunda seção discute sobre a temática políticas públicas, bem como os trabalhos correlatos ao tema. A terceira seção apresenta os procedimentos metodológicos empregados para estimar a eficiência técnica dos municípios - Data Envelopment Analysis (DEA) e para identificar os fatores que condicionam a eficiência - Modelo Tobit. Na quarta seção, são apresentados os resultados do estudo e, por fim, as principais considerações finais acerca do nível de eficiência, assim como das características dos municípios que explicam os escores de eficiência. 


\section{REFERENCIAL TEÓRICO}

\subsection{Formulação e Avaliação de Políticas Públicas}

Nas últimas décadas, conforme menciona Souza (2006), o termo política pública vem ganhando relevância. A referida autora comenta que a terminologia política pública surgiu nos Estados Unidos, focando na análise do Estado e suas instituições, do que propriamente na produção dos governos. Portanto, este termo nasceu no meio acadêmico, sem possuir nenhuma relação com as bases teóricas do papel do Estado, partindo para uma análise direta sobre as ações dos governos.

Matias-Pereira (2012, p. 89) conceitua política pública como "políticas compostas por normas, princípios e atos voltados a um objetivo determinado de interesse geral." Dias e Matos (2012, p. 11) explicam que a expressão política pública "engloba vários ramos do pensamento humano, sendo interdisciplinar, pois sua descrição abrange diversas áreas do conhecimento, como as Ciências Sociais Aplicadas." Ainda, os autores definem política pública como todas as ações realizadas pelo governo que irão promover a equidade social. Höfling (2001) explica que a política pública nada mais é do que a implementação, por parte do governo, de ações para determinado nicho populacional que considerar como prioritário. A autora relata que o entendimento da política pública não pode se restringir às políticas estatais, pois vai além deste conceito, uma vez que busca proteger o cidadão, conferindo a ele a possibilidade de redistribuição de renda e/ou benefícios sociais.

Souza (2006) apresenta um conceito sobre política pública que abrange uma visão mais ampla sobre o tema. Segundo a autora, política pública é uma área de conhecimento que busca colocar em prática as ações governamentais e, ao mesmo tempo, analisar estas ações de forma a poder corrigir os rumos propostos quando estes fogem da programação inicial.

Os atores das políticas públicas são os agentes que irão apresentar reinvindicações ou mesmo analisar, implementar e avaliar a formulação das políticas que irão contribuir para melhoria da qualidade de vida dos cidadãos. Silva, Jaccoud e Beghin (2005) explicam que estes atores podem ser grupos profissionais, setores privados, especialistas, dentre outros, que estão envolvidos direta ou indiretamente no desenvolvimento de políticas públicas.

Na perspectiva de Saravia (2006), a formulação das políticas públicas passa por três fases, quais sejam, formulação, implementação e reformulação. A fase da formulação abrange a etapa de definição de objetivos, do marco jurídico e financeiro que sustentará a política. O estágio da implementação está associado ao processo de alocação de recursos humanos, financeiros, tecnológicos e outros, para que a política seja de fato executada. E, por fim, a etapa referente à reformulação consiste na verificação das ações realizadas e os seus efeitos gerados à sociedade.

Neste contexto, a política pública torna-se um importante instrumento de gestão, em que as necessidades socioeconômicas e ambientais da população são observadas e analisadas. A partir delas, são elaboradas ações que buscam mitigar os efeitos negativos sobre a sociedade, de modo a maximizar o bem-estar social e promover a equidade social.

Ressalta-se que, no processo de formulação de políticas públicas, cada estágio tem seu grau de importância, não podendo deixar de dar atenção à avaliação das ações implementadas. Para tanto, pode-se fazer uso de indicadores sociais que possibilitam o monitoramento, por parte do poder público, das condições de vida da sociedade. Diante da necessidade de parâmetros de mensuração, diversos órgãos, como Organização das Nações Unidas (ONU) e Organização para a Cooperação e Desenvolvimento Econômico (OCDE), iniciaram um trabalho no sentido de elaborar indicadores sociais, de modo a permitir uma avaliação da qualidade de vida e do desenvolvimento.

Em meio a uma infinidade de índices existente no Brasil, pode-se mencionar o Índice Mineiro de Responsabilidade Social, criado pela FJP. Conforme a Fundação João Pinheiro (2013), este índice foi desenvolvido com o propósito de avaliar a situação de todos os municípios de Minas Gerais, englobando as dimensões (subíndices) renda, saúde, educação, segurança pública, gestão, habitação e meio ambiente, cultura e desporto e lazer. O referido índice demonstra a responsabilidade social dos municípios mineiros.

Dentre os subíndices considerados na composição do IMRS geral, destaca-se a dimensão meio ambiente, habitação e saneamento básico, que aborda aspectos referentes à salubridade ambiental, cobertura vegetal e parcela de áreas destinadas à preservação ambiental e acesso, uso e qualidade de serviços relacionados a tal dimensão. Este subíndice é obtido por uma média ponderada dos seguintes indicadores: percentual de cobertura vegetal por flora nativa; percentual de áreas de proteção integral; percentual de áreas de uso sustentável; percentual da população com acesso a abastecimento de água por rede geral; percentual da população em domicílios particulares permanentes, com banheiro de uso exclusivo dos moradores ou sanitário, e com coleta de esgoto sanitário via rede geral de esgoto ou pluvial ou fossa séptica; percentual da população em domićlios particulares permanentes com coleta direta ou indireta de lixo por serviço de limpeza; proporção de internações por doenças relacionadas ao saneamento ambiental inadequado; e esforço orçamentário em meio ambiente, saneamento e habitação. (FUNDAÇÃO JOÃO PINHEIRO, 2013).

Dadas as afirmações anteriores, Stefani, Nunes e Matos (2014) explicam que, mesmo o IMRS apresentando uma característica quantitativa, em que os escores variam entre zero e um, todo o processo de análise deste indicador deve se pautar sob a ótica qualitativa. Além disto, os autores afirmam que o IMRS permite captar as mais diversas características (heterogeneidade) do estado de Minas Gerais, fomentando avaliações sobre os processos de desenvolvimento socioeconômicos das diversas regiões de planejamento mineiras.

Destaca-se que essas dimensões que compõem o índice estão intimamente interligadas. Conforme Carmo e Távora Junior (2003), a qualidade de vida da população dos municípios pode ser melhorada por meio de investimentos em 
saneamento, que pode também contribuir para a melhoria da proteção ao meio ambiente, fazendo com que reduza a incidência de doenças causadas pelo uso de águas inapropriadas para o consumo humano.

\subsection{Estudos Relacionados}

Neste tópico, estão listadas algumas pesquisas relacionadas ao objeto de estudo, na busca de evidenciar um pouco sobre o estado da arte do tema abordado. No Brasil, tem sido realizado diversos trabalhos voltados para a mensuração da eficiência das ações e políticas governamentais, especialmente, nas áreas de educação e saúde.

Pode-se citar, inicialmente, o trabalho de Faria, Jannuzzi e Silva (2008), que estudaram a eficiência dos gastos públicos com saúde dos municípios fluminenses utilizando o método DEA. O estudo utilizou indicadores de educação, cultura, saúde e saneamento. Como resultado da pesquisa, os autores destacam que se deve ter cuidado com a forma funcional adotada para execução do DEA (inputs e outputs) e, principalmente, no que se refere aos indicadores sociais utilizados.

Fonseca e Ferreira (2009) analisaram a eficiência na utilização dos recursos na área de saúde, considerando como unidades de análise as microrregiões do estado de Minas Gerais. Como resultados, os autores relatam que as microrregiões mineiras, no contexto geral, apresentaram escores de eficiência relativamente bons, pois a maioria se encontrava acima da média do estado. No entanto, devido à heterogeneidade entre as microrregiões, evidenciam disparidades da gestão dos recursos para a área de saúde.

Valdevino et al. (2010) investigaram a eficiência dos serviços de saneamento básico dos municípios do estado do Tocantins no combate a endemias associadas à falta desses serviços, por meio do emprego do DEA. Considerando dados de 2016, no que diz respeito ao combate de doenças de transmissão hídrica, os autores observaram que os municípios menos eficientes teriam que diminuir consideravelmente a quantidade de casos para que alcançassem a fronteira de eficiência.

Outro estudo relacionado à eficiência dos municípios mineiros é o de Silva et al. (2012), em que os autores, por meio do modelo DEA, buscaram analisar a eficiência na alocação de recursos públicos nas áreas da saúde, educação e habitação, no ano de 2004. Os autores relatam que existe um lapso nos investimentos nas áreas do estudo, constatando-se, também, que as regiões carentes de Minas Gerais, como os Vales do Jequitinhonha e Norte de Minas, apresentam grande concentração de escores considerados eficientes. Além disto, expõem que a maioria dos municípios mineiros está na faixa de escores de médio a baixo.

Por sua vez, Nascimento, Costa e Olher (2015) realizaram um estudo utilizando a Análise Envoltória de Dados, com o objetivo de analisar a eficiência dos municípios da Zona da Mata de Minas Gerais, no que se refere à alocação de recursos na educação. Os autores utilizaram o gasto com educação per capita e o Índice Mineiro de Responsabilidade Social para a área de educação, identificando que apenas 13 municípios foram considerados eficientes, sendo que o IMRS é influenciado pelo PIB per capita e pelo gasto com educação per capita. Os resultados encontrados sugerem que os municípios ineficientes devem rever suas práticas de gestão municipal na área analisada.

Bittelbrunn et al. (2016) buscaram identificar, no período de 2012 a 2014, a eficiência dos estados brasileiros em relação aos gastos com saneamento. Na análise, foi empregado o método DEA, considerando tanto o retorno constante quanto o variado de escalas. Os autores constataram que os estados que apresentaram melhores práticas governamentais na área de saneamento básico foram Paraná, Tocantins e Minas Gerais, enquanto os menos eficientes foram o Amazonas, Rondônia, Amapá e Piauí. Pelos resultados, concluíram que, embora tenha ocorrido um aumento na eficiência dos estados no período analisado, o desempenho ainda é inferior ao esperado.

\section{METODOLOGIA}

Neste tópico, é descrito o procedimento metodológico empregado para obter a eficiência técnica dos municípios mineiros e identificar os condicionantes dos níveis de eficiência destas cidades.

\subsection{Delineamento da Pesquisa}

Para atingir o objetivo da pesquisa, foi necessário utilizar a abordagem quantitativa, que possibilitou obter a eficiência dos municípios mineiros e identificar os fatores que interferem no nível de eficiência relacionada às áreas de meio ambiente, habitação e saneamento. De acordo com Raupp e Beuren (2012), tal abordagem é constantemente aplicada em estudos que visam identificar e classificar a relação entre variáveis, por meio do emprego de instrumentos estatísticos, tanto no processo de coleta quanto no tratamento e análise dos dados.

Quanto aos meios empregados, a presente pesquisa caracteriza-se como bibliográfica, visto que buscou explorar, a partir de referências teóricas, o que já foi pesquisado sobre o assunto investigado. Segundo Vergara (2009), a pesquisa bibliográfica é de grande utilidade para se conhecer as contribuições científicas do passado sobre determinado fenômeno.

Este trabalho caracteriza-se, quanto aos fins (VERGARA, 2009), como explicativo, pois, além de estimar a eficiência municipal, buscou-se identificar os fatores que contribuem para a sua ocorrência. Conforme Gil (2008, p. 28), este tipo de pesquisa é o que mais aprofunda o estudo sobre dado fenômeno, visto que “[...] explica a razão, o porquê das coisas." Nesta pesquisa, busca-se explicar a relação entre o grau de eficiência dos municípios (variável dependente), no que se refere às áreas de meio ambiente, habitação e saneamento e características que o condicionam. 


\subsection{Análise Envoltória de Dados}

A mensuração da eficiência relativa de unidades produtoras que utilizam vários insumos para gerar múltiplos produtos pode ser realizada pela Análise Envoltória de Dados (DEA). A análise envoltória de dados é uma técnica não paramétrica, que se utiliza da programação matemática para analisar a eficiência das Unidades Tomadoras de Decisão (DMU) (FARREL, 1957; SCHEEL, 2001). Ferreira e Gomes (2009) comentam que a referida análise, também denominada Teoria da Fronteira, tem como fundamento modelos matemáticos não paramétricos, não permitindo inferências estatísticas. As DMUs podem ser entendidas como uma firma, município, entidade, ou outra unidade produtora.

Farrel (1957) afirma que a eficiência de uma DMU é uma medida relativa, determinada em relação ao melhor nível de eficiência verificado na prática. Assim, a fronteira de eficiência é construída a partir de insumos e produtos de cada unidade de análise observada, e não com base em valores estimados.

Na estimação da eficiência das DMUs, além da abordagem DEA, existe, na literatura, a fronteira estocástica. Ferreira (2005) explica a diferença básica entre essas duas abordagens. A primeira é não paramétrica e estima uma fronteira determinística, já a segunda é uma metodologia paramétrica que possui como base uma função estocástica. Ambos os procedimentos se assemelham no que tange à obtenção de uma fronteira para constatação da eficiência das unidades em análise.

Ferreira (2005) ainda esclarece que o uso do procedimento paramétrico demandaria um conhecimento mais profundo sobre a função de produção, para se ter uma estimação adequada. No entanto, devido às características de mercado, este conhecimento nem sempre é possível, o que torna o uso do instrumento paramétrico mais restritivo. Neste caso, apesar de a DEA apresentar limitações, como alta sensibilidade a outliers e não ser possível fazer inferência estatística, torna-se mais apropriada na estimação da eficiência, em decorrência de não se conhecer com detalhes a forma funcional da função de produção.

$\mathrm{Na}$ análise de eficiência, deve-se levar em conta a distinção entre eficiência técnica e eficiência alocativa, que, combinadas, obtém-se a eficiência econômica, conforme especifica Coelli et al. (2005). Estes autores definem eficiência técnica como a competência de uma unidade produtora alcançar o máximo de produtos/resultados, dada certa quantidade de insumos. A eficiência alocativa consiste na habilidade de uma unidade tomadora de decisão empregar os insumos em quantidades ótimas, dados os preços, minimizando custos.

A DEA apresenta duas versões em modelagem: Modelo de Retornos Constantes à Escala (CCR), formulado por Charnes, Cooper e Rhodes (1978), e o Modelo de Retornos Variáveis à Escala (BCC), elaborado por Banker, Charnes e Cooper (1984). No CCR, assume-se que os pesos das variáveis que compõem o modelo possuem as mesmas cargas, implicando em variação proporcional no produto quando se altera o insumo. No BCC, a diferença em relação ao retorno constante é a inserção de uma restrição de convexidade no Problema de Programação Linear (PPL), indicando que a DMU analisada apresenta retornos crescente, decrescente ou constante.

Os modelos utilizados na DEA possuem duas orientações básicas, a orientação-insumo e orientação-produto. Os modelos com orientação-produto buscam medir o volume de produção máxima possível a partir de uma quantidade fixa de insumos, isto é, maximiza a produção a partir de insumos disponíveis. Já a orientação-insumo, busca minimizar a utilização de insumos no processo produtivo, mantendo-se o nível de produção (FERREIRA; GOMES, 2009). De outra forma, enquanto a orientação-produto investiga o quanto pode aumentar o produto sem alterar as quantidades empregadas de insumo, a orientação-insumo avalia o quanto pode reduzir na quantidade de insumo sem modificar o montante produzido (COELLI et al., 2005).

Pelos modelos DEA, é possível identificar, para cada unidade ineficiente, os seus benchmarks, que são DMUs de referência, sendo definidos pela projeção das unidades ineficientes na fronteira de eficiência, que é realizada conforme a orientação do modelo.

Neste trabalho, para identificar a eficiência técnica dos municípios mineiros, foi utilizada a orientação-produto, em virtude de fundamentar-se na maximização do resultado, dado os recursos disponíveis. No que diz respeito ao modelo empregado, neste estudo, utilizou-se o de retornos variáveis à escala.

Desta forma, o modelo de programação linear utilizado foi o constante na Equação 1, conforme Ferreira e Gomes (2009):

$$
\max \emptyset
$$

\section{Sujeito a:}

$$
\begin{gathered}
-\phi Y_{i}+Y \lambda \geq 0 \\
x_{i}-X \lambda \geq 0 \\
N_{1}^{\prime} \lambda=1 \\
\lambda \geq 0
\end{gathered}
$$

em que $\phi$ é um escalar cujo valor está entre um e infinito, sendo que a eficiência técnica $(\theta)$ da DMU é obtida pela razão $1 / \phi ; \lambda$ é um vetor, cujos valores são calculados de forma a obter a solução ótima; $y_{i}$ são os produtos; e $x_{i}$ são os insumos.

Como a DEA é sensível à presença de outliers, podendo comprometer a estimação, foi empregada a metodologia proposta por Stošić e Sousa (2003). Os autores desenvolverem um procedimento chamado jackstrap, que é uma mescla entre o método jackknife (determinístico) e bootstrap (estocástico). Inicialmente, por meio do jackknife, cada DMU é 
excluída da amostra e efetua-se o cálculo da eficiência, para avaliar a influência de cada unidade na mensuração da eficiência. Em seguida, é utilizado o método de reamostragem bootstrap, considerando a informação de influência obtidas na etapa inicial (jackknife).

Após esses passos, obtém-se o estimador denominado leverage, que segundo Stošić e Sousa (2003), mede o impacto da remoção de cada unidade de decisão do conjunto amostral sobre os escores de eficiência das demais DMUs. Assim, o leverage trata-se do desvio-padrão da medida de eficiência antes e depois da exclusão da DMU. O leverage da j-ésima DMU pode ser definido como a seguir:

$$
l_{j}=\sqrt{\frac{\sum_{k=1 ; k \neq j}^{K}\left(\theta_{k j}^{*}-\theta_{k}\right)^{2}}{K-1}}
$$

em que k são as DMUs, variando de um até K; $j$ representa a DMU removida; e, $\theta$, os indicadores de eficiência.

A partir da informação do leverage, é possível identificar os dados considerados discrepantes. Para tanto, é necessário utilizar algum critério de corte para remover as observações. Segundo Stošić e Sousa (2003), uma forma de efetuar este procedimento é multiplicar a média do leverage global pelo logaritmo do número de DMU da amostra. Assim, a DMU que possuir leverage acima deste valor pode ser tratada como outlier, sendo, então, excluída da amostra.

\subsection{Modelo Tobit}

Após estimar os escores de eficiência, realizou-se um segundo estágio, que consistiu em explicar o resultado de eficiência encontrado para os municípios. Para tanto, empregou-se o modelo Tobit. Segundo Ervilha et al. (2013), este modelo é amplamente utilizado consorciado com o modelo Data Envelopment Analysis.

O modelo pressupõe que $x_{i}$ é uma variável observada e $y_{i}$ nem sempre é verificável, assumindo em alguns casos valor zero. Cameron e Trivedi (2009) descrevem o modelo Tobit com a variável latente não observável $y^{\star}$, conforme Equação 3:

$$
y_{i}^{*}=x_{i}^{\prime} \beta+\varepsilon_{i}, i=1, \ldots, N
$$

em que $\varepsilon_{i} \sim N\left(0, \sigma^{2}\right)$ e $x_{i}$ denotam um vetor $(\mathrm{K} \times 1)$ de regressores exógenos perfeitamente observáveis. Se $y^{\star}$ é observável, pode-se estimar naturalmente pelo método dos Mínimos Quadrados Ordinários (MQO). No entanto, neste caso, os estimadores de MQO são considerados viesados e inconsistentes.

Sendo a variável $y_{i}$ observada, esta é relacionada com a variável latente $y_{i}^{\star}$ por meio da seguinte regra:

$$
y=\left\{\begin{array}{l}
y^{*} \text { se } y^{*}>L \\
L \text { se } y^{*} \leq L
\end{array}\right.
$$

Cameron e Trivedi (2009) explicam que a probabilidade de uma observação censurada é dada por $\operatorname{Pr}\left(y^{\star} \leqslant L\right)=\operatorname{Pr}\left(x_{i}^{\prime} \beta+\varepsilon \leqslant L\right)=\phi\left\{\left(\mathrm{L}-x_{i}^{\prime} \beta / \sigma\right)\right\}, \phi\left(^{\star}\right)$ em que é a função de distribuição acumulada normal padrão. Os autores afirmam que a média truncada ou o valor esperado de $y$ para um conjunto de observações não censuradas pode ser obtida pela Equação 4:

$$
E\left(y_{i} \mid x_{i}, y_{i}>L\right)=x_{i}^{\prime} \beta+\sigma \frac{\phi\left\{x_{i}^{\prime} \beta-L / \sigma\right\}}{\phi\left\{L-x_{i}^{\prime} \beta / \sigma\right\}}
$$

em que $\phi\left(^{*}\right)$ é a densidade normal padrão. A exatidão da equação 4 depende do pressuposto $\varepsilon_{i} \sim N\left(0, \sigma^{2}\right)$

Portanto, o modelo Tobit é indicado em situações em que a variável explicada assume valores acima ou abaixo de dado limite, como é o caso da eficiência dos municípios que varia entre zero e um. Neste caso, tem-se o que se chama de amostra censurada que pode ser contornado por meio da utilização do referido modelo. 


\subsection{Amostra, Variáveis e Coleta de Dados}

A amostra do presente estudo foi constituída pelos municípios de Minas Gerais, considerando dados do ano de 2010. Do total de municípios mineiros, foram excluídos os que não apresentavam dados de alguma variável, bem como aqueles considerados outliers pelo teste Jackstrap.

Para estimação da eficiência, as variáveis do modelo foram definidas de acordo com a Fundação João Pinheiro (2013), como se segue:

\section{- Inputs}

a) Percentual de esgoto tratado: consiste na razão entre o volume de esgoto tratado e o volume total de esgoto gerado pela população urbana.

b) Percentual dos domicílios com acesso a abastecimento de água por rede geral: são os domicílios particulares permanentes com acesso a abastecimento de água por rede geral dividido pelo número total de domicílios particulares permanentes do município.

c) Percentual dos domicílios atendidos com rede geral de esgoto ou pluvial ou fossa séptica que têm banheiro ou sanitário: trata-se da relação entre os domicílios particulares permanentes atendidos com rede geral de esgoto ou pluvial ou fossa séptica, que tem banheiro ou sanitário e o número total de domicílios particulares permanentes do município.

d) Percentual dos domicílios atendidos com coleta direta ou indireta de lixo por serviço de limpeza: é a razão entre o número de domicílios particulares permanentes atendidos com coleta direta de lixo, por serviço de limpeza ou em caçamba de serviço de limpeza e o total de domicílios particulares permanentes da cidade.

\section{- Output}

a) Índice Mineiro de Responsabilidade Social: indicador social que representa a dimensão meio ambiente, habitação e saneamento básico.

Com o intuito de explicar os resultados da eficiência dos municípios de Minas Gerais, as variáveis utilizadas na estimação do modelo Tobit foram: densidade demográfica, parcela de população urbana, Produto Interno Bruto (PIB) per capita, gasto consolidado per capita com Habitação, Saneamento e Meio Ambiente (GHSMA), variáveis dummies que representam a existência de conselhos de meio ambiente e habitação.

Os dados, tanto das variáveis utilizadas para obter os escores de eficiência quanto do modelo Tobit, para o ano de 2010, foram coletados na plataforma do IMRS disponibilizada pela FJP.

\section{RESULTADOS E DISCUSSÃO}

Nesta seção, apresenta-se uma estatística descritiva das variáveis utilizadas, a eficiência técnica dos municípios que compõem a amostra, bem como os determinantes desta eficiência.

\subsection{Eficiência municipal das ações socioambientais}

A seguir, mostra-se uma estatística descritiva do produto e insumos considerados na estimação da eficiência e dos escores de eficiência dos municípios mineiros. Do total de municípios que compõe o estado de Minas Gerais (853), após excluir aqueles que apresentavam ausência de dados e os considerados outliers, a amostra foi constituída por 663 municípios, correspondendo a 78\% das cidades mineiras. Ressalta-se que os municípios excluídos por apresentarem dados discrepantes, a maioria possui pequeno porte, com população média inferior a oito mil habitantes.

A Tabela 1 mostra a estatística descritiva dos fatores inseridos no modelo DEA, assim como dos resultados de eficiência encontrados para os municípios da amostra.

Tabela 1 - Estatística descritiva das variáveis

\begin{tabular}{l|c|c|c|c|c|c|}
\hline Estatísticas & $\begin{array}{c}\text { Escore } \\
\text { Eficiência }\end{array}$ & IMRS & $\begin{array}{c}\text { Domicilios } \\
\text { com abast. } \\
\text { de água (\%) }\end{array}$ & $\begin{array}{c}\text { Domicilios } \\
\text { com trat. de } \\
\text { esgoto (\%) }\end{array}$ & $\begin{array}{c}\text { Domicilios } \\
\text { com coleta } \\
\text { lixo (\%) }\end{array}$ & $\begin{array}{c}\text { Esgoto } \\
\text { tratado (\%) }\end{array}$ \\
\hline Média & 0,781 & 0,441 & 74,03 & 63,83 & 76,12 & 7,79 \\
Desvio Padrão & 0,137 & 0,101 & 14,32 & 22,98 & 16,41 & 18,91 \\
Mínimo & 0,302 & 0,170 & 29,46 & 0,91 & 25,21 & 0,00 \\
Máximo & 1,000 & 0,794 & 99,57 & 98,37 & 99,88 & 99,54 \\
\hline
\end{tabular}

Fonte: Dados da pesquisa 
Pela Tabela 1, verifica-se que o escore de eficiência médio obtido foi de 0,781, variando entre 0,302 (valor mínimo) e 1,000 (valor máximo). O IMRS apresentou média de 0,441, valor máximo de 0,794 e mínimo de 0,170. Os domicílios com abastecimento de água, rede de tratamento de esgoto e coleta de lixo, apresentaram valores máximos superiores a 98\%. Quanto ao percentual de esgoto que é tratado, permitindo o reaproveitamento da água, identificou-se que há município que trata em torno de $99 \%$ do volume de esgoto gerado, enquanto que a maior parte das cidades mineiras não possui um sistema de tratamento do esgoto. A média de tratamento de esgoto dos municípios analisados é de apenas $7,79 \%$ do total gerado.

Para melhor entender os resultados da eficiência das ações socioambientais na geração do IMRS, foram construídos critérios de categorização das DMUs, conforme os escores de eficiência, tomando-se como base a média e o desvio-padrão. Neste sentido, na Figura 1, pode-se visualizar a eficiência dos municípios de Minas Gerais.

Figura 1 - Eficiência das ações socioambientais dos municípios mineiros

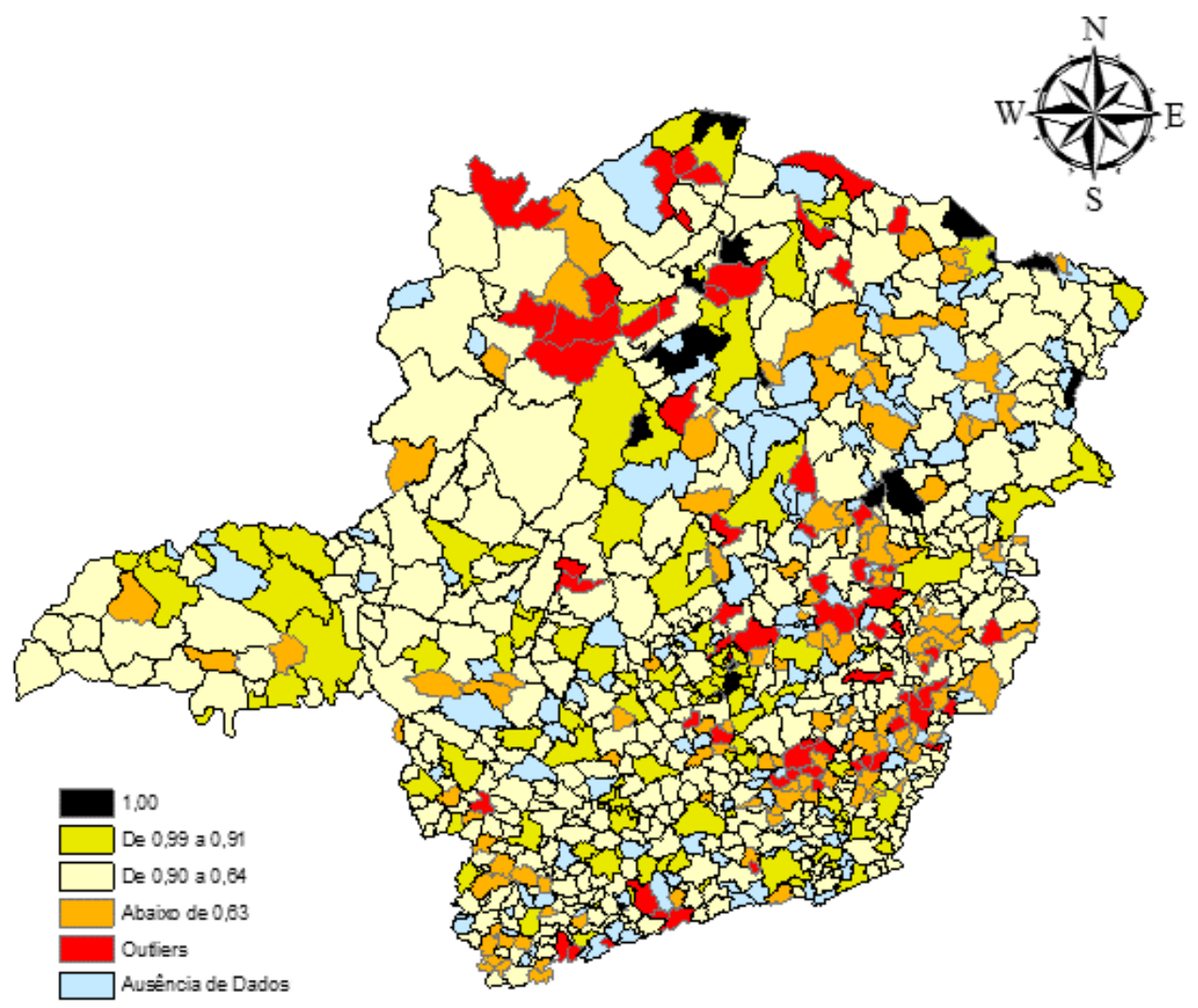

Fonte: Dados da pesquisa

Pelos resultados, os municípios que obtiveram eficiência relativa igual a 1,00 totalizaram 17, correspondendo a apenas 2,6\% do total dos municípios da amostra. Esses municípios identificados como eficientes servem de benchmarking para os demais. Portanto, uma análise de seus esforços voltados para meio ambiente, habitação e saneamento básico pode gerar informações necessárias à melhoria do desempenho das outras cidades do estado. As cidades consideradas como referências foram Belo Horizonte, Ibirité, Vespasiano, Pirapora, São Lourenço, Coração de Jesus, Varzelândia, Água Boa, São Sebastião do Maranhão, Ninheira, Divisópolis, Japonvar, Santa Cruz de Minas, Divisa Alegre, Juvelina, Bertópolis, Glaucilândia. Nota-se que, boa parte das cidades mencionadas é de pequeno porte.

Os municípios que obtiveram escores de eficiência entre 0,91 a 0,99, que, de certa forma, podem ser considerados eficientes, somaram aproximadamente $17 \%$ da amostra, o que representa 112 cidades. Destaca-se que estes são, em sua maioria, de médio e grande porte. No intervalo entre 0,64 a 0,90 , há quase $62 \%$ do total da amostra dos municípios, sendo o maior grupo (413 cidades). As cidades mineiras que auferiram escores abaixo de 0,63 somaram cerca de $18 \%$ da amostra (121 municípios). Aqueles municípios excluídos da amostra, por não apresentarem dados suficientes para a estimação da DEA e por serem outliers, totalizaram $123(14,2 \%)$ e 67 (7,8\%), respectivamente.

$\mathrm{Na}$ Tabela 2, apresenta-se os dez municípios maiores, os dez intermediários e a mesma quantidade de cidades menores com base em suas respectivas populações, além de dados de algumas variáveis, de maneira a caracterizar melhor as unidades analisadas. 
Tabela 2 - Características dos municípios do estado de Minas Gerais em relação à população

\begin{tabular}{|c|c|c|c|c|}
\hline \multicolumn{5}{|c|}{ Dez municipios maiores } \\
\hline Municípios & $\begin{array}{l}\text { Escores de } \\
\text { Eficiência }\end{array}$ & $\begin{array}{c}\text { Densidade } \\
\text { Populacional }\end{array}$ & $\begin{array}{l}\text { GHSMA per } \\
\text { capita }\end{array}$ & PIB per capita \\
\hline Belo Horizonte & 1,000 & $7.192,41$ & 282,99 & $21.748,30$ \\
\hline Uberlândia & 0,985 & 146,70 & 180,94 & $30.463,70$ \\
\hline Contagem & 0,997 & $3.104,44$ & 88,97 & $30.743,30$ \\
\hline Juiz de Fora & 0,962 & 360,03 & 13,61 & $16.055,00$ \\
\hline Betim & 0,984 & $1.091,92$ & 149,94 & $74.950,60$ \\
\hline Montes Claros & 0,925 & 101,52 & 14,68 & $12.436,50$ \\
\hline Ribeirão das Neves & 0,979 & $1.915,80$ & 36,32 & $6.499,20$ \\
\hline Uberaba & 0,964 & 65,18 & 233,20 & $24.173,00$ \\
\hline Governador Valadares & 0,975 & 112,26 & 141,41 & $12.687,50$ \\
\hline Ipatinga & 0,900 & $1.441,79$ & 32,30 & $30.904,60$ \\
\hline Média & 0,9671 & $1.553,20$ & 117,43 & $26.066,17$ \\
\hline \multicolumn{5}{|c|}{ Dez municipios Intermediários } \\
\hline Municípios & $\begin{array}{c}\text { Escores de } \\
\text { Eficiência }\end{array}$ & $\begin{array}{l}\text { Densidade } \\
\text { Populacional }\end{array}$ & $\begin{array}{l}\text { GHSMA per } \\
\text { capita }\end{array}$ & PIB per capita \\
\hline Coqueiral & 0,773 & 31,34 & 117,84 & $11.399,50$ \\
\hline Riacho dos Machados & 0,695 & 7,12 & 10,58 & $4.506,90$ \\
\hline Carneirinho & 0,730 & 4,58 & 88,92 & $22.219,40$ \\
\hline Arceburgo & 0,892 & 58,65 & 5,53 & $25.256,80$ \\
\hline Ipuiúna & 0,743 & 31,91 & 3,80 & $13.080,10$ \\
\hline Tombos & 0,818 & 33,71 & 60,70 & $7.145,40$ \\
\hline Antônio Dias & 0,483 & 12,15 & 28,13 & $8.028,40$ \\
\hline Ninheira & 1,000 & 8,85 & 43,83 & $4.807,40$ \\
\hline Conceição da Aparecida & 0,694 & 27,87 & 1,56 & $12.881,10$ \\
\hline Rubim & 0,875 & 10,27 & 12,00 & $5.818,20$ \\
\hline Média & 0,7703 & 22,64 & 37,29 & $11.514,32$ \\
\hline \multicolumn{5}{|c|}{ Dez municipios menores } \\
\hline Municipios & $\begin{array}{c}\text { Escores de } \\
\text { Eficiência }\end{array}$ & $\begin{array}{l}\text { Densidade } \\
\text { Populacional }\end{array}$ & $\begin{array}{l}\text { GHSMA per } \\
\text { capita }\end{array}$ & PIB per capita \\
\hline Senador Cortês & 0,798 & 20,28 & 147,34 & $8.027,30$ \\
\hline Tapiraí & 0,630 & 4,57 & 40,04 & $16.872,10$ \\
\hline Queluzito & 0,667 & 12,11 & 42,91 & $11.286,40$ \\
\hline Seritinga & 0,864 & 15,61 & 140,95 & $8.870,00$ \\
\hline Santo A. do Rio Abaixo & 0,529 & 16,59 & 0,42 & $7.133,90$ \\
\hline Antônio Prado de Minas & 0,650 & 19,62 & 0,00 & $8.818,80$ \\
\hline Doresópolis & 0,835 & 9,38 & 68,17 & $12.552,70$ \\
\hline Grupiara & 0,890 & 7,10 & 162,85 & $12.712,10$ \\
\hline Cedro do Abaeté & 0,891 & 4,29 & 105,57 & $9.373,50$ \\
\hline Serra da Saudade & 0,702 & 2,43 & 237,84 & $13.768,80$ \\
\hline Média & 0,7456 & 11,20 & 94,61 & $10.941,56$ \\
\hline
\end{tabular}

Fonte: Dados da pesquisa

Considerando a Tabela 2, nota-se que, dentre os dez maiores municípios de acordo com a população, Belo Horizonte foi o único que apresentou eficiência máxima. Estes municípios exibiram uma média do escore de eficiência de 0,9671. 
Em relação aos dez municípios menores, estes tiveram uma média de 0,7456 de eficiência, sendo $23 \%$ inferior à média dos dez municípios mais populosos do estado.

Em termos de densidade populacional, percebe-se uma grande disparidade entre os dez maiores e os dez menores municípios analisados. Enquanto os municípios considerados maiores apresentaram um valor médio de 1.553,20 hab/ $\mathrm{km}^{2}$, os menores tiveram densidade demográfica relativamente baixa, de 11,20 hab/ $\mathrm{km}^{2}$. Desta forma, pode-se inferir que os dez maiores municípios demandam mais ações relacionadas à infraestrutura, saúde, saneamento básico e outros serviços de competência dos municípios, pois o quantitativo de indivíduos que requerem tais serviços é bem superior. No entanto, não quer dizer que os dez municípios menores não necessitam dos respectivos serviços, pelo contrário, precisam destes na mesma qualidade que os demais.

Na Tabela 2 também é apresentada a variável GHSMA, que representa o esforço financeiro per capita com habitação, saneamento e meio ambiente. O primeiro grupo de municípios analisado obteve uma média per capita de $\mathrm{R} \$ 117,43$, enquanto no segundo, a média foi de $\mathrm{R} \$ 94,61$, indicando que as cidades mais populosas possuem um gasto individual superior às menos populosas, em torno de $19 \%$. Estes gastos refletem a política municipal para o atendimento a estes setores sociais de grande relevância para a sociedade. No entanto, ressalta-se que não necessariamente os municípios que dispenderam mais recursos per capita, nestas áreas, apresentaram melhores resultados. Assim, deve-se analisar o contexto de cada município com maior rigor.

Pelo PIB per capita dos municípios, Tabela 2, percebe-se que os dez maiores e os dez menores tiveram uma média de $\mathrm{R} \$ 26.000,00$ e $\mathrm{R} \$ 11.000,00$, respectivamente. A riqueza gerada pelo município pode ser um bom indicador da capacidade de o município investir em mecanismos que contribuam para a melhoria do bem-estar da população. Portanto, quanto maior for a riqueza produzida, presume-se que melhor é a condição de investir em ações socioambientais que proporcionem qualidade de vida aos cidadãos.

Por sua vez, na Tabela 2, encontram-se também os dez municípios considerados intermediários, baseados no tamanho populacional. Para a definição destes, utilizou-se a técnica estatística da mediana que divide a amostra em duas partes exatamente iguais. Assim, pode-se verificar um escore médio de eficiência de 0,77, com destaque para o município de Ninheira, que apresentou escore de eficiência igual a 1,00, e Antônio Dias, com o menor escore $(0,483)$. Constatou-se que a amplitude do escore de eficiência foi de 0,517, ou seja, variando de 0,483 a 1,00. No que se refere à densidade populacional, gastos com habitação, saúde e meio ambiente e PIB per capita, estes foram, em média, de 22,64 habitantes/ $\mathrm{km}^{2}, \mathrm{R} \$ 37,29$ per capita e $\mathrm{R} \$ 11.514,32$, respectivamente.

Na Tabela 3, pode-se visualizar os dez municípios da amostra que apresentaram os piores e melhores escores de eficiência relativa.

Tabela 3 - Dez piores e melhores municípios em termos de escores de eficiência (Continua)

\begin{tabular}{l|c|c|c|c}
\hline \multicolumn{5}{|c}{$\mathbf{1 0}$ Municipios com Piores Escores de Eficiência } \\
\hline Municípios & Escores Eficiência & $\begin{array}{c}\text { Densidade } \\
\text { populacional }\end{array}$ & $\begin{array}{c}\text { GHSMA } \\
\text { per capita }\end{array}$ & PIB per capita \\
\hline Gonçalves & 0,302 & 22,28 & 0,25 & $6.522,50$ \\
São Domingos das Dores & 0,315 & 88,80 & 29,87 & $6.822,70$ \\
Onça do Pitangui & 0,363 & 12,56 & 101,53 & $12.623,50$ \\
Moeda & 0,409 & 30,35 & 3,96 & $6.936,40$ \\
Santa Bárbara do Leste & 0,424 & 72,13 & 5,75 & $5.876,10$ \\
Dores do Turvo & 0,428 & 19,36 & 8,25 & $6.165,80$ \\
Cantagalo & 0,441 & 29,56 & 35,04 & $5.715,00$ \\
Catuji & 0,452 & 16,03 & 3,81 & $5.026,60$ \\
Comendador Gomes & 0,455 & 2,85 & 0,78 & $34.723,50$ \\
Itaverava & 0,458 & 20,40 & 0,01 & $4.940,60$ \\
Média & $\mathbf{0 , 4 0 4 7}$ & $\mathbf{3 1 , 4 4}$ & $\mathbf{1 8 , 9 3}$ & $\mathbf{9 . 5 3 5 , 2 7}$ \\
\hline
\end{tabular}


Tabela 3 - Dez piores e melhores municípios em termos de escores de eficiência (Conclusão)

\begin{tabular}{l|c|c|c|c}
\hline \multicolumn{5}{c}{10 Municipios com Melhores Escores de Eficiência } \\
\hline Municipios & $\begin{array}{c}\text { Escores } \\
\text { Eficiência }\end{array}$ & $\begin{array}{c}\text { Densidade } \\
\text { populacional }\end{array}$ & $\begin{array}{c}\text { GHSMA } \\
\text { per capita }\end{array}$ & PIB per capita \\
\hline Belo Horizonte & 1,00 & 7192,41 & 282,99 & $21.748,30$ \\
Ibirité & 1,00 & 2170,91 & 16,26 & $7.953,30$ \\
Pirapora & 1,00 & 97,16 & 135,20 & $19.756,80$ \\
São Lourenço & 1,00 & 720,21 & 109,84 & $10.582,90$ \\
Coração de Jesus & 1,00 & 11,69 & 15,63 & $6.066,30$ \\
Varzelândia & 1,00 & 23,49 & 17,87 & $4.631,80$ \\
Água Boa & 1,00 & 11,49 & 5,84 & $5.776,60$ \\
São Sebastião do Maranhão & 1,00 & 20,60 & 19,14 & $4.674,10$ \\
Ninheira & 1,00 & 8,85 & 43,83 & $4.807,40$ \\
Divisópolis & 1,00 & 15,86 & 14,41 & $5.690,60$ \\
Média & $\mathbf{1 , 0 0}$ & $\mathbf{1 . 0 2 7 , 2 6}$ & $\mathbf{6 6 , 1 0}$ & $\mathbf{9 . 1 6 8 , 8 1}$ \\
\hline
\end{tabular}

Fonte: Dados da Pesquisa

Pelos resultados da Tabela 3, nota-se que a média de escore de eficiência dos dez piores municípios foi de 0,4047, e que, dentre eles, o município de Gonçalves foi o que apresentou menor escore, no valor de 0,302, estando abaixo da média do grupo em torno de $34 \%$. No que diz respeito ao gasto per capita consolidado com habitação, saneamento e meio ambiente per capita, constata-se que estes municípios que apresentaram níveis baixos de eficiência aplicaram uma parcela ínfima de recursos nestas áreas, o que pode ter refletido negativamente no desempenho dos mesmos.

Por sua vez, ao analisar os dez municípios com melhores escores de eficiência, classificados pelo tamanho da população, percebe-se que a média da densidade demográfica foi 32 vezes maior que os de piores eficiência. Já os gastos per capita com habitação, saúde e meio ambiente foram 3,5 vezes maiores. No entanto, o PIB per capita destes municípios com maior escore de eficiência foi aproximadamente 3\% menor do que os de piores escores. Uma possível explicação para este fato, pode estar associada à riqueza do município quando relativizada com tamanho populacional. Com exceção dos municípios de Água Boa, São Sebastião do Maranhão e Ninheira, todos os demais possuem Conselho Municipal de Meio Ambiente e Habitação.

Constatou-se que 90\% dos dez municípios com piores escores de eficiência não têm Conselho Municipal de Habitação e 70\% não possuem também Conselho Municipal de Meio Ambiente, o que pode contribuir para os baixos escores. No entanto, os dez municípios maiores em termos populacionais, que apresentaram eficiência acima de 0,90, possuem os Conselhos Municipais de Habitação e Meio Ambiente, propiciando o desenvolvimento de ações socioambientais de forma mais efetiva, gerando, portanto, melhores indicadores de reponsabilidade social.

Destaca-se que o Conselho Municipal de Habitação é um órgão de fiscalização, consultivo e deliberativo, cujo objetivo é implementar políticas públicas destinadas à habitação dentro dos limites geográficos do município. Já o Conselho Municipal de Meio Ambiente, por analogia, é um órgão destinado à implementação de políticas públicas ambientais, a nível municipal para auxiliar os gestores na busca de melhores condições ambientais que promovam melhores índices de qualidade de vida. Desta forma, a ausência destes Conselhos pode contribuir para baixo desempenho de ações relacionadas com as respectivas áreas.

Objetivando efetuar uma comparação entre as cidades eficientes e ineficientes, a Tabela 4 resume informações a respeito dos insumos e produto utilizados na estimação da eficiência. Assim, apresentam os 17 municípios $100 \%$ eficientes, e, no caso dos ineficientes, foi considerado o mesmo número de cidades caracterizadas pela eficiência máxima.

Tabela 4 - Análise descritiva dos insumos e produto dos municípios eficientes e não eficientes

\begin{tabular}{l|c|c|c|c}
\hline \multicolumn{5}{c}{ Inputs e Outputs dos municipios 100\% eficientes } \\
\hline Variáveis & Média & Desvio Padrão & Mínimo & Máximo \\
\hline IMRS & 0,389 & 0,191 & 0,170 & 0,739 \\
Percentual Dom. com abastecimento de água & 79,22 & 20,80 & 38,08 & 99,57 \\
Percentual Dom. com rede de esgoto & 40,91 & 37,10 & 0,91 & 98,37 \\
Percentual Dom. com coleta de lixo & 65,51 & 29,92 & 25,21 & 99,88 \\
Percentual de esgoto tratado & 6,14 & 9,50 & 0,00 & 27,06 \\
\hline
\end{tabular}




\begin{tabular}{l|c|c|c|c}
\hline \multicolumn{5}{c}{ Inputs e Outputs dos municipios menos eficientes } \\
\hline Variáveis & Média & Desvio Padrão & Mínimo & Máximo \\
\hline IMRS & 0,396 & 0,058 & 0,299 & 0,531 \\
Percentual Dom. com abastecimento de água & 40,59 & 5,98 & 29,46 & 47,50 \\
Percentual Dom. com rede de esgoto & 47,19 & 12,06 & 31,64 & 70,12 \\
Percentual Dom. com coleta de lixo & 59,12 & 18,53 & 34,38 & 98,10 \\
Percentual de esgoto tratado & 13,45 & 27,23 & 0,00 & 80,00 \\
\hline
\end{tabular}

Fonte: Dados da pesquisa

Conforme Tabela 4, é possível perceber que as 17 cidades com eficiência máxima, apresentaram uma média do IMRS de 0,389, enquanto que as 17 menos eficientes, o valor médio foi de 0,396. Analisando os resultados dos insumos, nota-se que as variáveis percentual de domicílios com rede de esgoto e percentual de esgoto tratado nos municípios $100 \%$ eficientes apresentaram valores inferiores aos municípios menos eficientes. Assim, constata-se que os menos eficientes demandam um esforço maior no que tange a estas duas variáveis, para poder gerar um IMRS semelhante ao dos municípios eficientes.

Pela metodologia do IMRS, este varia entre zero e um. No entanto, conforme Tabela 1, verificou-se que, no caso dos municípios mineiros estudados, tal índice oscilou entre 0,170 a 0,794, com média de 0,441. Como pode-se perceber, de acordo com a Tabela 4, o valor médio do IMRS dos municípios 100\% eficientes pode ser considerado relativamente baixo, inferior à média dos municípios da amostra. Porém, esperava-se que estes municípios possuíssem um IMRS médio mais elevado, uma vez que apresentaram eficiência máxima.

Por fim, destaca-se os municípios que alcançaram eficiência relativa máxima, e mais, serviram de referências para as demais cidades da amostra, ou seja, são as DMUs que devem ser observadas pelas cidades ineficientes, de modo que estas possam adotar práticas que melhorem os seus desempenhos, em termos de desenvolver ações voltadas para os setores de saneamento e habitação, que gerem índices mais eficientes. Assim, pode-se mencionar os seguintes municípios: Japonvar, que serviu como referência 618 vezes; Divisa Alegre, que foi apontado em um total de 415 vezes; e, São Lourenço, que foi referência em 324 ocasiões. Pondera-se que as duas primeiras cidades, consideradas de pequeno porte, buscaram desenvolver as suas ações relacionadas a meio ambiente, habitação e saneamento básico, de maneira a maximizar a sua responsabilidade social.

\subsection{Fatores determinantes da eficiência dos municípios mineiros}

Para identificar os fatores condicionantes da eficiência das cidades mineiras estudadas, no que diz respeito às ações relacionadas às dimensões saneamento, meio ambiente e habitação, efetuou-se a estimação do modelo Tobit, considerando como variável dependente o escore de eficiência gerado por meio da DEA, com pressuposição de retorno variável à escala e orientação-produto. Os resultados da estimação do modelo podem ser visualizados na Tabela 5.

Tabela 5 - Fatores associados à eficiência dos municípios mineiros

\begin{tabular}{|c|c|c|c|}
\hline Variáveis & Efeito Marginal & Erro-Padrão & P-valor \\
\hline DENSPOP & 0,0000629 & 0,0000233 & 0,007 \\
\hline POPHURB & 0,0059971 & 0,0002298 & 0,000 \\
\hline GHSMA & 0,0000706 & 0,0000757 & 0,352 \\
\hline CONMH & 0,0038422 & 0,0072886 & 0,598 \\
\hline CONMMA & 0,0167095 & 0,0078371 & 0,033 \\
\hline PIBPC & $-9.72 e-07$ & $3,58 \mathrm{e}-07$ & 0,007 \\
\hline Constante & 0,3473004 & 0,0153587 & 0,000 \\
\hline
\end{tabular}

Fonte: Dados da pesquisa

A partir do modelo estimado, conforme Tabela 5, observa-se que as variáveis Gastos com Habitação, Saneamento e Meio Ambiente (GHSMA) e existência de Conselho Municipal de Habitação (CONMH) não foram significativas, sendo, portanto, irrelevantes para explicar a variação nos escores de eficiência dos municípios mineiros.

Os coeficientes das variáveis Densidade Populacional (DENSPOP), proporção da População Urbana (POPHURB) apresentaram significância estatística ao nível de 1\%, com sinal positivo. No entanto, esperava-se que estas variáveis 
contribuíssem para uma pior eficiência dos municípios, uma vez que cidades com maiores aglomerações populacionais e maior percentual de população vivendo em áreas urbanas tendem a ser mais ineficientes nas suas ações voltadas para essas áreas.

Outra variável que apresentou significância do coeficiente a 5\% foi a existência de Conselho Municipal de Meio Ambiente (CONMMA), podendo-se inferir que a existência de tal conselho influencia positivamente no nível de eficiência dos municípios mineiros. Portanto, aqueles municípios que apresentam este conselho tendem a ser mais eficientes em suas ações. Esta é uma variável importante, pois o conselho tem como finalidade formular e implementar políticas públicas voltadas às questões ambientais, que estão ligadas diretamente ao bem-estar dos indivíduos.

No caso do PIB per capita (PIBPC), apesar de seu coeficiente ter sido significativo a 1\%, espera-se que este contribuísse para um maior nível de eficiência técnica, tendo em vista que o município com maior riqueza tende a gerar mais receita própria, possuindo melhor condição de investir nestas áreas. No entanto, para que o investimento proporcione melhor resultado socioambiental, dependerá da forma como estes recursos serão geridos pelo poder público.

\section{CONSIDERAÇÕES FINAIS}

As áreas de saneamento, habitação e meio ambiente são de grande importância de atuação do gestor público, pois são setores que demandam empenhos financeiros para minimizar problemas que podem vir a afetar diretamente a saúde popular, bem como o seu bem-estar. Em outras palavras, o baixo investimento governamental, nestes segmentos, pode proporcionar a proliferação de doenças que afetarão diretamente o sistema público de saúde e, consequentemente, a qualidade de vida do cidadão.

Tendo em vista que o objetivo do trabalho foi verificar se as ações desenvolvidas pelo poder público estão sendo eficientes na promoção de práticas ambiental e socialmente corretas que promovam a maximização do bem-estar, pode-se destacar, a partir dos resultados, que 17 municípios mineiros alcançaram eficiência máxima. Deste total, 11 cidades (65\%) possuem população inferior a 20 mil habitantes e seus gastos médios com saneamento, habitação e meio ambiente per capita foram de $\mathrm{R} \$ 20,43$. Os outros seis municípios são de médio e grande porte e apresentaram gasto per capita de $\mathrm{R} \$ 93,51$.

Constatou-se também que os dez menores municípios mineiros em termos populacionais apresentaram uma média do escore de eficiência e gasto com saneamento, habitação e meio ambiente inferiores em comparação aos de maiores populações. Assim, as cidades menos eficientes devem observar aqueles municípios que desenvolvem melhor as políticas relacionadas às áreas de saneamento, habitação e meio ambiente, para que possam aprimorar as suas práticas, alcançando resultados mais interessantes.

Destaca-se que os esforços financeiros dos municípios em tratar o esgoto gerado pela população, fazer a coleta de lixo, abastecer os domicílios com água potável e captar adequadamente o esgoto sanitário não devem ser reduzidos, por se tratarem de serviços básicos para a população. Portanto, considera-se que os municípios ineficientes devem buscar aprimorar a forma de desenvolver as suas ações, para que possam ter um desempenho mais satisfatório, de modo a elevar o IMRS. E que ao aprimorar as práticas de gestão das áreas mencionadas, a população passará a ter um ganho de bem-estar e também uma provável melhor aplicação dos recursos públicos destinados a estes setores.

É importante salientar que este estudo visa contribuir com apontamentos para os gestores públicos, no que tange à eficiência dos municípios referente às práticas nas áreas de saneamento, habitação e meio ambiente, pois são vertentes que afetam diretamente a qualidade de vida e bem-estar dos cidadãos. Desta forma, torna-se um balizador de ações para o planejamento de políticas públicas específicas.

Considerando que, neste estudo, a análise pautou em identificar o efeito de algumas variáveis sobre a eficiência em dado ano, sugere-se, como pesquisas futuras, testar outros fatores que possam explicar o nível de eficiência em relação às áreas analisadas, assim como verificar se o efeito das mesmas variáveis alterou ao longo do tempo.

\section{REFERÊNCIAS}

BANKER, R. D.; CHARNES, A.; COOPER, W. W. Some models for estimating technical and scale inefficiencies in data envelopment analysis. Management Science, v. 30, n. 9, p. 1078-1092, 1984.

BITTELBRUNN, F. et al. Estudo da eficiência dos gastos com saneamento básico dos estados brasileiros e DF entre 2012 a 2014 por meio de Análise Envoltória de Dados. In: Congresso Brasileiro de Custos, 23., 2016, Porto de Galinhas. Anais eletrônicos [...]. Porto de Galinhas: ABC, 2016. Disponível em: https://anaiscbc.emnuvens.com.br/anais/article/viewFile/4216/4217. Acesso em: 19 fev. 2019.

CAMERON. A. C.; TRIVEDI, P. K. Microeconometrics using stata. 2009.

CARMO, C. M. do; TÁVORA JUNIOR, J. L. Avaliação da eficiência técnica das empresas de saneamento brasileiras utilizando a metodologia DEA. In: ENCONTRO NACIONAL DE ECONOMIA, 21., 2003, Porto Seguro. Anais eletrônicos [...]. Porto Seguro: ANPEC, 2003. Disponível em: http://www.anpec.org.br/encontro_2003.htm. Acesso em: 04 jun. 2015.

CHARNES, A.; COOPER, W. W.; RHODES, E. Measuring the efficiency of decision making units. European Journal of Operational Research, v. 2, p. 429-444, 1978.

COELLI, T. J. et al. An introduction to efficiency and productivity analysis. 2. ed. New York: Springer. 2005. 
DIAS, R.; MATOS, F. Políticas Públicas: princípios, propósitos e princípios. São Paulo: Editora Atlas, 2012.

ERVILHA, G. T. et al. Os determinantes da eficiência dos gastos públicos com segurança nos municípios mineiros: uma análise a partir da metodologia DEA. In: CONGRESSO ANUAL DA ASSOCIAÇÃO MINEIRA DE DIREITO E ECONOMIA, 5., 2013, Belo Horizonte. Anais eletrônicos [...]. Belo Horizonte: PUC/Minas, 2013. Disponível em: http://www.congresso.amde.org.br/index.php/ CONGRESSO/V_AMDE/paper/view/20. Acesso em: 01 jun. 2015.

FARREL, M. J. The Measurement of Productive Efficiency. Journal of the Royal Statistical Society, v. 120, n. 3, p. 253-290, 1957.

FARIA, F. P.; JANNUZZI, P. M.; SILVA, S. J. Eficiência dos gastos municipais com saúde e educação: uma investigação através da análise envoltória no estado do Rio de Janeiro. Revista de Administração Pública, Rio de Janeiro, n. 42, p. 155-177, 2008.

FERREIRA, C. M. de C.; GOMES; A. P. Introdução à análise envoltória de dados: teoria, modelos e aplicações. Viçosa: UFV, 2009.

FERREIRA, M. A. M. Eficiência Técnica e de Escala de Cooperativas e Sociedade de Capital na Indústria de Laticínios do Brasil. 2005. Tese (Doutorado em Economia Aplicada) - Universidade Federal de Viçosa, Viçosa, 2005.

FONSECA, P. C.; FERREIRA, M. A. M. Investigação dos níveis de eficiência na utilização de recursos no setor de saúde: uma análise das microrregiões de Minas Gerais. Revista Saúde e Sociedade, São Paulo, v. 18, n. 2, p. 199-213, 2009.

FUNDAÇÃO JOÃO PINHEIRO (FJP). Índice Mineiro de Responsabilidade Social (IMRS) - 2010. 2013. Disponível em: http:// www.fjp.mg.gov.br/. Acesso em: 25 maio 2015.

GIL, A. C. Métodos e Técnicas de Pesquisa Social. 6. ed. São Paulo: Editora Atlas, 2008.

HÖFLING, E. M. Estado e Políticas (Públicas) Sociais. Caderno CEDES. n. 55. 2001.

MATIAS-PEREIRA, J. Finanças Públicas: foco na política fiscal, no planejamento e orçamento público. 6. ed. São Paulo: Editora Atlas, 2012

NASCIMENTO, L. M.; COSTA, I. S.; OLHER, B. S. Gastos públicos com educação: uma análise da eficiência dos municípios da Zona da Mata Mineira. Revista de Ciências da Educação, Americana, n. 32, p. 119-143, 2015.

NOSSO FUTURO comum. Comissão Mundial sobre o Meio Ambiente e Desenvolvimento. Rio de Janeiro: FGV, 1991. Disponível em: http://pt.scribd.com/doc/12906958/Relatorio-Brundtland-Nosso-Futuro-Comum-Em-Portugues. Acesso em: 15 abr. 2015.

NOVAES, W. ECO-92: Avanços e Interrogações. Revista Estudos Avançados, São Paulo, v. 6, p.79-93, 1992.

RAUPP, F. M.; BEUREN, I. M. Metodologia da Pesquisa Aplicável às Ciências Sociais. In: BEUREN, I. M. (Org.). Como elaborar trabalho monográficos em contabilidade: teoria e prática. 3. ed. São Paulo: Editora Atlas, 2012.

SARAVIA, E. Introdução à Teoria da Política Pública. In: SARAVIA, E.; FERRAREZI, E. (Org.). Políticas públicas: coletânea, Brasília: ENAP, 2006. 2 v.

SCHEEL, H. Undesirable outputs in efficiency valuations. European Journal of Operational Research, v. 132, p. 400-410, 2001.

SECRETARIA DO TESOURO NACIONAL (STN). Estados e Municípios. 2015. Disponível em: http://www3.tesouro.fazenda. gov.br/estados_municipios/. Acesso em: 10 abr. 2015.

SILVA, A. A. P. et al. Eficiência na alocação de recursos públicos destinados à educação, saúde e habitação em municípios mineiros. Revista Contabilidade, Gestão e Governança, v. 15, n. 1, p. 96-114, 2012.

SILVA, F. B. da; JACCOUD, L.; BEGHIN, N. Políticas Sociais no Brasil: participação social, conselhos e parcerias. In: JACCOUD, L. (org.). Questão Social e Políticas Sociais no Brasil Contemporâneo. Brasília: IPEA, 2005. p. 373-407.

SOARES, T. J.; HIGUCHI, N. A convenção do clima e a legislação brasileira pertinente, com ênfase para a legislação ambiental no Amazonas. Revista Acta Amazônica, Amazônia, v. 36, p. 573-580, 2006.

SOUZA, C. Políticas Públicas: uma revisão da literatura. Sociologias, Porto Alegre, n. 16, p.20-45, 2006. Disponível em: http:// www.scielo.br/pdf/soc/n16/a03n16. Acesso em: 23 jun. 2015.

STEFANI, J.; NUNES, M. A.; MATOS, R. Índice Mineiro de Responsabilidade Social e sua Dinâmica na região de Planejamento Jequitinhonha/Mucuri. Caderno de Geografia, Belo Horizonte, v. 24, n. 41, 2014.

STOŠIĆ, B. D.; SOUSA, M. da C. S. de. Jackstrapping DEA Scores for Robust Efficiency Measurement. Brasília, DF: Universidade Federal de Brasília, 2003. (Texto para Discussão, n. 291).

VALDEVINO, A. A. F. et al. Avaliação da eficiência dos serviços de saneamento básico no combate às endemias nos municípios do Estado do Tocantins. Informe Gepec, Toledo, v. 14, n. 2, p. 166-181, jul./dez. 2010.

VERGARA, S. C. Projetos e Relatórios de Pesquisa em Administração. São Paulo: Editora Atlas, 2009.

WAKIM, V. R.; VERGARA, F. E.; MAGALHÃES, E. A. Uso do método dose-resposta na mensuração de impactos na lucratividade da produção de arroz irrigado na microrregião de Formoso do Araguaia no estado do Tocantins. Revista em Agronegócios e Meio Ambiente, Paraná, v. 5, p. 103-133, 2012. 